\section{Kidney \\ Blood Pressure \\ Research}

Review

\title{
The Rehabilitation Role in Chronic Kidney and End Stage Renal Disease
}

\author{
Domenico Intiso
}

Rehabilitation Medicine and Neuro-Rehabilitation Unit, Scientific Institute, Hospital 'Casa Sollievo della Sofferenza', San Giovanni Rotondo (Foggia), Italy

\section{Key Words}

Chronic kidney disease $\cdot$ Disability $\bullet$ Rehabilitation $・$ Exercise $\bullet$ Hemodialysis

\begin{abstract}
Chronic kidney disease (CKD) worldwide is rising markedly becoming a priority public health problem. The progression of CKD cause functional limitation and severe disability with poor quality of life. The aim of present review was to highlight the effect of rehabilitation in CKD and ESRD subjects. The rehabilitative process is unique in treating disabled people according to a holistic approach with the aim of supporting a person's independent living and autonomy. CKD are associated with an increased risk of functional impairment, independent of age, gender, and co-morbidities. Clinicians should counsel patients with CKD including frail elder people to increase physical activity levels and target that regular physical activity including aerobic or endurance exercises training benefits health. In old subjects with CKD and multiple functional impairments, the traditional disease based model should be changed to individualized patient-centered approach that prioritizes patient preferences. Patients receiving haemodialysis have a considerably lower exercise tolerance, functional capacity, and more muscle wasting than healthy subjects or patients with less severe CKD. Exercise training or comprehensive multi-dimensional strategy and goal-oriented intervention should be also provided in ESRD older subjects. Structured prevention programs based on reducing the risk factors for CKD and rehabilitative strategies could reduce disability occurrence.
\end{abstract}

Copyright $\odot 2014$ S. Karger AG, Basel

\section{Introduction}

The burden of the chronic kidney disease

Since 2002, the chronic kidney disease (CKD) is defined as the presence of kidney damage or reduced glomerular filtration rate (GFR) less than $60 \mathrm{~mL} / \mathrm{min} / 1.73 \mathrm{~m}^{2}$ that is present for three months or more [1]. According to GFR, there are five stages of CKD from 1 to 5 with GFR $>90 \mathrm{~mL} / \mathrm{min} / 1.73 \mathrm{~m}^{2}$ (kidney damage with normal or increased kidney function) through GFR $<15 \mathrm{~mL} / \mathrm{min} / 1.73 \mathrm{~m}^{2}$ (kidney failure and haemodialysis), respectively. Age, 


\section{Kidney Blood Pressure Research}

\begin{tabular}{l|l}
\hline Kidney Blood Press Res 2014;39:180-188 \\
\hline DOI: $10.1159 / 000355795$ & (C) 2014 S. Karger AG, Basel
\end{tabular}

Published ontIne: July 29, 2014

www.karger.com/kbr

Intiso: Rehabilitation in Chronic Kidney Disease

hypertension, and diabetes are the key predictors of new onset secondary CKD. The high prevalence and incidence of CKD and end-stage renal disease (ESRD) is a global challenge. A recent epidemiological survey in a large population sample showed that the overall incidence of a definite diagnosis of CKD was 479 per 100,000 person-years [2]. Furthermore, studies from around the world have reported a broadly similar prevalence between $10 \%$ and $16 \%$ in adults [3] depending on the diagnostic criteria used. The number of patients with CKD worldwide is rising markedly becoming a priority public health problem. The rise in CKD worldwide most probably reflects the global epidemic of type 2 diabetes and the ageing of the populations in developed countries, with a higher incidence and prevalence in elderly people. The incidence of CKD has been shown to increase with age and nearly half of old people suffers from this condition [4,5]. Likewise, the prevalence of CKD varies from $23.4 \%$ to $35.8 \%$ in people aged 64 years or older [6]. Because high income countries population is dramatically chancing as the elderly represent the fastest growing demographic segment, it is predictable that a large number of old subjects suffering from CKD and ESRD will need care and assistance. Furthermore, the number of people with diabetes worldwide, currently around 154 million, is set to double within the next 20 years, and the increase will be most notable in the developing world. The progression of CKD cause functional limitations and severe disability with poor quality of life that require proper rehabilitative strategies, particularly in old people [7] who also suffer from several co-morbidities. The transition from CKD to ESRD constitute high clinical risk situations with substantial healthcare costs. Despite patients with ESRD comprise only a small percentage of people with CKD [8], the cost of treating these patients is substantial and poses a great challenge to provision of care. In Europe, less than $0.1 \%$ of the population needs renal replacement therapy, which accounts for $2 \%$ of the healthcare budget [9]. Structured and well resourced primary prevention programs based on reducing the risk factors for CKD and rehabilitative strategies adjunct to proper interventions during the renal disease could make a big difference in reducing the impact that CKD will predictably have on disability occurrence and related social cost [10]. The aim of present review was to highlight the role and effect of rehabilitation in CKD and ESRD subjects.

\section{Rehabilitation role and rehabilitative project}

Rehabilitation has been defined by the World Health Organization (WHO) as"the use of all means aimed at reducing the impact of disabling and handicapping conditions and at enabling people with disabilities to achieve optimal social integration". This definition incorporates clinical rehabilitation but also, importantly, endorses the concept of social participation as requiring a matching of the social environment to the needs of people with disabilities. The overall aim of rehabilitation is to enable people with disabilities to lead the life that they would wish, given any restriction imposed on their activities by impairments resulting from illness or injury as well as from their personal context [11]. The rehabilitative process is unique in treating people according to a holistic approach or a bio-psycho-social model with the aim of supporting a person's independent living and autonomy. Rehabilitation has been demonstrated effective and efficient in reducing the burden of disability and enhancing the opportunities for disabled people. On the base of clinical, affective and functional evaluation, physiatrists have to plan the rehabilitative project including all structural body and functional areas that need of reparative and rehabilitative interventions. Rehabilitative project has to forecast time and intervention type, to individuate recoverable limitations and the functional objectives that can be reached. Furthermore, suitable rehabilitative methods and techniques have to be described in reaching the results as well as the specific role of involved personnel staff in the rehabilitative process. The role of rehabilitation intervention and how much specific strategies can affect functional recovery have to be communicated and discussed with patients and his/her family. Indeed, discussion regarding goals of care and advance care planning ought to be common place in executing rehabilitative project. 


\section{Kidney Blood Pressure Research}

Patients and caregivers should be discouraged from setting unrealistic rehabilitation goals, whenever required functional abilities are not recoverable. The rehabilitation project should be tailored on the individual effective needs of CKD people according to the holistic approach considering stage of disease, complications and co-morbidities. As a patientcentered process, it has to be appropriate to optimize both activity and participation to ameliorate person's quality of life. People with CKD could complain of complex functional impairments and multi-system clinical disorders needing of specialized care and specific rehabilitative interventions. In this case, the rehabilitative project can be only executed by an interdisciplinary approach with a multi-professional team work that include physiatrist, geriatrician, nephrologist and other medical practitioner such as nurses, social worker, and occupational or physical therapist in order to obtain the best benefit by the one's own expert and competent contribute.

\section{Chronic Kidney disease and disability}

CKD are associated with an increased risk of functional impairment, independent of age, gender, co-morbidities, and cardiovascular events [12]. The association with functional limitation has been observed not only in patients with ESRD [13] and moderate-severe CKD (mean GFR $25 \mathrm{ml} / \mathrm{min} / 1.73 \mathrm{~m}^{2}$ ) [14], but also in subjects with milder CKD (mean GFR 50 $\mathrm{ml} / \mathrm{min} / 1.73 \mathrm{~m}^{2}$ ) [12]. Several causes can contribute to limitations occurrence in these subjects including anemia, protein-energy malnutrition, lower muscle strength, metabolic disturbances resulting in reduction exercises tolerance, independence and ability to perform activities of daily living (ADL). Because ability decline occurring in adult CKD subjects, rehabilitative strategies should be planned on the base of age, functional limitations, residual abilities, participation and co-morbidities. In CKD adult subjects with retained ADL and IADL (instrumental activity of daily living) capacities, clinicians have to recommend active life style with regular physical exercise to prevent functional decline. In subjects who present reduced abilities and more complex limitations, a multi-disciplinary approach should be carried out.

Exercise training for adults with chronic kidney disease

The ability and capacity to perform ADL (physical functioning) is severely reduced in adults with CKD [15]. Low levels of physical activity and poor physical functioning are strongly associated with mortality and poor clinical outcomes in these patients, regardless of treatment modality [16]. During the last 30 years, there have been a significantly increasing number of published studies concerning the effect of regular exercise training in adults with CKD. The first seminal step of rehabilitation intervention is based on the exercise prescription. Clinicians should counsel the patients with CKD to increase physical activity levels and inform them that there is scientific evidence that regular exercise benefits health [17]. Exercise regimens are based on the frequency, intensity and duration of exercise training as well as the type of activity and the individual's initial level of physical fitness. The training regimen should include aerobic, resistance and flexibility activities. Aerobic exercise training should build up to at least 30 min of moderate intensity exercise on 5 days per week using a gradual approach. By now, there is evidence for significant beneficial effects of regular exercise on physical fitness, walking capacity, cardiovascular dimensions (e.g. blood pressure and heart rate), health-related quality of life and some nutritional parameters in adults with CKD [15]. Physical activity has the potential to positively impact upon aerobic and functional ability, and the quality of life of all CKD patients independent of the stage of the disease process [18]. Regular exercisers have better quality of life, physical functioning, sleep quality scores, report fewer physical activity limitations and are less affected by pain or poor appetite. In models adjusted for demographics, co-morbidities and socio-economic indicators, mortality risk was $27 \%$ lower among CKD subjects performing regular exercisers compared to subjects who performed poor physical activity [19]. 


\section{Kidney Blood Pressure Research}

\begin{tabular}{l|l}
\hline Kidney Blood Press Res 2014;39:180-188 \\
\hline DOI: $10.1159 / 000355795$ & (C) 2014 S. Karger AG, Basel
\end{tabular}

Published ontIne: July 29, 2014 www.karger.com/kbr

Intiso: Rehabilitation in Chronic Kidney Disease

Disability and Rehabilitation intervention in CKD elder subjects

Because average levels of GFR tend to decrease with age, CKD becomes increasingly prevalent with advancing age, and nearly half of old people suffers from this condition [4]. Physical impairment can be detected in the early stages of elder CDK people [20,21]. In elders, CKD is associated with the development of disability independent of body composition, physical performance and comorbidity [20]. In comparison with those with normal renal function, the elderly patients with CKD are more likely to have increased co-morbidities, walking impairments and decrement in quality of life. Older subjects with GFR less than 45 $\mathrm{mL} / \mathrm{min} / 1.73 \mathrm{~m}^{2}$ have an odds of IADL or basic activities of daily living (BADL) decline more than threefold greater compared with those without CKD [7]. Furthermore communitydwelling older adults with CKD show an accelerate decline in life-space mobility trajectory that produces reduced ability to move to outside one's home, neighborhood, or town and to engage in social activities and participation including family events and religious services [22]. Walking impairment is fairly common in elderly CKD people and strongly associates with all-cause mortality [23]. Several rehabilitative strategies and approaches can be applied in these people to delay the functional decline and to ameliorate the residual abilities (table 1). In early stage of CKD, proper exercises have to be planned in those who have mild comorbidities and not severe limitations. Physical activity including aerobic and resistance exercises have been recommended producing positive effects on cardio-respiratory fitness, physical function and self-reported health [24]. Moderate to high-intensity strength training improves physical performance, muscle mass and quality of life in CDK [25] as well as dialysis older patients [26]. Of course, not all CKD subjects have to perform regular exercises. In addition to that reported by American College of Cardiology Foundation/American Heart association, several contraindications are specific to CKD patients such as symptomatic hearth arrhythmias, pulmonary congestion, and peripheral oedema. On the other hand, specific rehabilitative interventions have to be tailored whenever multiple co-morbidities such as multi-joints arthritis, sarcopenia, heart failure and neurological disturbances contribute to the disability. Recently a different model has been proposed in caring elder CKD people that should change from traditional disease based model to individualized patient-centered approach [22]. An individualized approach prioritizes patient preferences and embraces the notion that observed signs and symptoms often do not reflect a single unifying disease process, and instead reflect the complex interplay between many different factors. This care method could result particularly positive in frail old people with CKD. These subjects are mostly inclined toward hospitalization, disability and death. Thus, it is crucial to develop interventions in decreasing adverse health outcomes. A large number of papers have reported that also frail elder people can benefit from regular physical activity including aerobic or endurance exercises training [27]. Among frailty factors, one of most important is loss of muscle mass. Although data remain controversial, studies have revealed that aerobic exercises can increase muscular mass of extremities in elderly [28]. The right rehabilitative interventions should be planned on the functional ability of elders and tailored by more structured and interdisciplinary approaches as functional decline advances [29]. Interdisciplinary care team including physiatrist, geriatrician, nephrologist and other medical practitioner knowledgeable in the care of older adults such as nurses, social worker, and occupational or physical therapist could be more effective than usual a single or disease-centered approach in treating multi-system disorders of frail old people with CKD. Occupational therapy can be an essential rehabilitative strategy in those suffering from CKD and multiple co-morbidities that affect functional abilities and ADLs. The use of assistive devices is a common intervention used to meet the goal of maintaining independence and assistive tools are commonly recommended for ADLs. They include dressing sticks, long handled shoe horns, long handled sponges, button hooks, shower seats, and three-in-one commodes. These items have been shown to be effective in minimizing energy output and improving function with self care and ADLs in patients with functional deficits from orthopedic and neuromuscular diseases. Correct techniques can save energy, increase time efficiency, and decrease frustration. Rehabilitative intervention can help to find the best 


\section{Kidney \\ Blood Pressure Research}

Table 1. Rehabilitative strategies in old people with CKD and ESRD

\begin{tabular}{|c|c|}
\hline Early stage of CKD & $\begin{array}{l}\text { physical activity including aerobic and resistance exercises } \\
\text { producing positive effects on cardio-respiratory fitness, physical } \\
\text { function and self-reported health }\end{array}$ \\
\hline & $\begin{array}{l}\text { moderate-to high-intensity strength training improves physical } \\
\text { performance, muscle mass and quality of life }\end{array}$ \\
\hline $\begin{array}{l}\text { Multiple co-morbidities and } \\
\text { mild disability }\end{array}$ & $\begin{array}{cl}\text { individualized patient-centered approach: } \\
\checkmark & \text { physical activity including aerobic exercises } \\
\checkmark & \text { resistance exercises } \\
\checkmark & \text { proprioceptive neuromuscular facilitation } \\
\checkmark & \text { posture and balance control } \\
\checkmark & \text { joints mobilization and spine flexibility exercises } \\
\checkmark & \text { endurance, muscle strength and muscular stretching } \\
\checkmark & \text { gait training }\end{array}$ \\
\hline $\begin{array}{l}\text { Frail CKD/ESRD } \\
\text { dwelling-people }\end{array}$ & $\begin{array}{l}\text { individualized patient-centered approach according functional } \\
\text { limitations and residual ability; } \\
\text { address limitations and focus on patients priority and family or care- } \\
\text { givers participation; } \\
\text { goals-oriented interventions and functional areas of interventions } \\
\text { with supervised sessions; } \\
\text { patients and family educations; } \\
\checkmark \quad \text { physical activity including aerobic exercises } \\
\checkmark \quad \text { proprioceptive neuromuscular facilitation } \\
\checkmark \quad \text { posture and balance control } \\
\checkmark \quad \text { joints mobilization } \\
\checkmark \text { muscular stretching } \\
\checkmark \text { gait training } \\
\checkmark \text { occupational therapy } \\
\checkmark \text { speech and cognitive rehabilitation }\end{array}$ \\
\hline $\begin{array}{l}\text { Frail CKD/ESRD people } \\
\text { requiring hospitalization }\end{array}$ & $\begin{array}{l}\text { comprehensive multi-dimensional strategy and goal-oriented } \\
\text { approach; } \\
\text { discussion regarding goals of care and advance care planning ought } \\
\text { to be common place for such patients; } \\
\text { specialized ward and interdisciplinary care team; } \\
\text { geriatric hemodialysis rehabilitation care }\end{array}$ \\
\hline \multicolumn{2}{|c|}{$\mathrm{CKD}=$ chronic kidney disease ESRD = end stage renal disease } \\
\hline
\end{tabular}

technique or equipment for particular situation and recommend when a caregiver will have to provide more assistance. A further essential role of occupational therapy is environmental and home living adaptation for elders with functional limitation who are at risk of falls that are the leading cause of injury and associated morbidity in elderly. In these subjects proper programs include home hazard assessments by trained individuals, removal or modification of identified hazards, installation of safety devices such as handrails on stairs and grab bars on bathrooms, and improvements in lighting [29]. Falls may lead to decreased mobility, hospitalization, depressive symptoms, functional decline, decreased social activity and poor quality of life [30,31]. All older adults with and without CKD at risk of falling should be offered an exercise program incorporating balance, gait, and strength training. Since fall risk can depend on several factors, a single approach can be insufficient. To date, several trials have demonstrated that multi-component and multi-factorial interventions resulted in an approximately $30 \%$ relative risk reduction in fall rate [32]. 


\section{Kidney Blood Pressure Research}

Kidney Blood Press Res 2014;39:180-188

DOI: 10.1159/000355795 2014

(C) 2014 S. Karger AG, Basel

www.karger.com/kbr

Intiso: Rehabilitation in Chronic Kidney Disease

\section{Hemodialitic patients ad rehabilitation}

The association between ESRD and functional impairment is well established [13]. Crosssectional reports have found that individuals with ESRD have lower physical functioning than the general population. Furthermore, ESRD subjects receiving maintenance haemodialysis (HD) have a considerably lower exercise tolerance, functional capacity, endurance and strength, and more muscle wasting and fatigue than healthy subjects or patients with less severe CKD who do not yet need renal replacement therapy [33]. Similar rehabilitative strategies delivered in CKD persons can be applied to dialysis subjects, particularly the exercise training. Individual recommendations by stage and/or treatment modality of kidney disease do not presently exist, however, the following suggestions may guide exercise prescription for the CKD/ESRD patient. Patients with peak $\mathrm{VO}_{2}$ values $\left(<17.5 \mathrm{mlkg}^{-1} \mathrm{~min}^{-1}\right)$ may obtain the largest survival benefit from exercise training [34]. Before starting exercise therapy, patients should be evaluated to define their suitability for exercise and to tailor individualized exercise prescriptions by exercise tolerance and functional capacity tests. Same recommendations and contraindications for older adults (65 years and above) of the American College of Sports Medicine and the American Heart Association [35], can be applied to patients with HD [36]. Benefits associated with exercise training are improved peak $\mathrm{VO}_{2}$ cardiac function, quality of life, and sympatho-adrenal activity [37]. Significant improvements in lean body mass, quadriceps muscle area, knee extension, hip abduction and flexion strength have been also reported [37]. Exercise training may be delivered in non-dialysis time, either as outpatients or at home, and also during dialysis, termed interdialytic exercise. Sophisticated machine such as leg press and free weights have been used to improve strength and to preserve physical function. On the other hand, simple and cheap elastic bands that can be used for resistance exercises during dialysis sessions may be an attractive alternative [38]. Doubts remain about the proper physical programs to obtain benefit, but no differences has been found between intra-dialytic versus home-based aerobic exercise training on physical function and vascular parameters in HD patients [39]. It should be emphasized that the most frail and incapacitated patients are probably those most in need of physical rehabilitation as a part of their clinical care. Although dialysis initiation is associated with a functional decline that is independent of age, gender, and prior functional status, this finding is more dramatic in old people. Sterky et al. observed that dialysis elderly subjects had 50\% less functional capacity than gender- and age-matched healthy subjects [40]. Only $13 \%$ of subjects after one year of HD maintain stable functionality [13]. The accelerate functional decline that occurs in dialysis old people promote mobility impairment, falls, fractures and functional limitations predisposing HD subjects to increased health utilization and long-term institutionalization. According to data from the US Data System, $25 \%$ of patients starting dialysis are over the age of 75 years and older patients represent the fastest growing group on dialysis [41, 42]. Elderly subjects with HD share many of same co-morbidities including diabetes, coronary artery disease, heath congestive failure, multilevel arthritis, pain, neuropathy, affective disorders and cognitive impairments that produce severe functional limitation and decrement of quality of life. A step-by step approach selecting the outcome to improve [43] and more recently, a patient centered intervention rather than disease treatment has been proposed [22]. In elderly subjects with advanced CKD, providers have to be prepared to adopt an integrative, individualized oriented-patient approach. Comprehensive multi-dimensional strategy and goal-oriented intervention should be provided in ESRD older subjects presenting multiform disability and requiring hospitalization. In this way, specialized geriatric rehabilitation units with on-site dialysis have been proposed in which integrated multidisciplinary care by experts in rehabilitation, geriatric medicine, and nephrology and reciprocal continued medical education among staff can help older dialysis patients with new-onset functional decline return to their home $[44,45]$. Discussion regarding goals of care and advance care planning ought to be common place for such patients. Patients and caregivers should be discouraged from setting unrealistic "rehabilitation goals," such as attaining a level of independence that 


\section{Kidney \\ Blood Pressure Research}

the patient has not had for several years or reversing a permanent impairment [46]. On average, the life expectancy of HD subjects aged more than 75 years is estimated to be 2.6 to 3.2 years from the dialysis initiation [47]. Since, these patients have increased risk of early death, it is need to be determined whether patients and their families prefer more effort be directed at achieving quantity of life versus quality of life [48].

\section{Conclusion}

The number of patients with CKD worldwide is rising markedly becoming a priority public health problem. Rehabilitation is effective and efficient in reducing the burden of disability and enhancing activities and participation for disabled people. Exercise training or comprehensive multi-dimensional strategy and goal-oriented intervention should be provided in CKD and ESRD subjects according to clinical condition and functional impairments. Since severe CKD/ESRD disabled subjects present complex dysfunction, goals and expected outcomes of treatment should be discussed with the patient and caregiver. Structured prevention programs based on reducing the risk factors for CKD and rehabilitative strategies could reduce disability occurrence and related social cost.

\section{Disclosure Statement}

The author of this article confirm that there are no conflicts to state.

\section{References}

$>1$ Levey AS, de Jong PE, Coresh J El Nahas M, Astor BC, Matsushita K, Gansevoort RT, Kasiske BL, Eckardt KU: The definition, classification, and prognosis of chronic kidney disease: a KDIGO Controversies Conference report. Kidney Int 2011;80:17-28.

-2 van Blijderveen JC, Straus SM, Zietse R, Stricker BH, Sturkenboom MC, Verhamme KM: A population-based study on the prevalence and incidence of chronic kidney disease in the Netherlands. Int Urol Nephrol 2014;46:583-592.

3 Mahmoodi BK, Matsushita K, Woodward M, Blankestijn PJ, Cirillo M, Ohkubo T, Rossing P, Sarnak MJ, Stengel B, Yamagishi K, Yamashita K, Zhang L, Coresh J, de Jong PE, Astor BC; Chronic Kidney Disease Prognosis Consortium: Associations of kidney disease measures with mortality and end-stage renal disease in individuals with and without hypertension: a meta-analysis. Lancet 2012;380:1649-1661.

4 Stengel B, Metzger M, Froissart M, Rainfray M, Berr C, Tzourio C, Helmer C: Epidemiology and prognostic significance of chronic kidney disease in the elderly—the Three-City prospective cohort study. Nephrol Dial Transplant 2011;26:3286-3295.

-5 Formiga F, Ferrer A, Cruzado JM, Padros G, Fanlo M, Roson B, Pujol R: Geriatric assessment and chronic kidney disease in the oldest old: the Octabaix study. Eur J Intern Med 2012;23:534-538.

-6 Zhang QL, Rothenbacher D: Prevalence of chronic kidney disease in population-based studies: systematic review. BMC Public Health 2008;8:117.

7 Bowling CB, Sawyer P, Campbell RC, Ahmed A, Allman RM: Impact of chronic kidney disease on activities of daily living in community-dwelling older adults. J Gerontol A Biol Sci Med Sci 2011;66:689-694.

8 Coresh J, Astor BC, Greene T, Eknoyan G, Levey AS: Prevalence of chronic kidney disease and decreased kidney function in the adult US population: third national health and nutrition examination survey. Am J Kidney Dis 2003;41:1-12.

-9ysaght MJ: Maintenance dialysis population dynamics: current trends and long-term implications. J Am Soc Nephrol 2002;13:37-40. 


\section{Kidney \\ Blood Pressure Research}

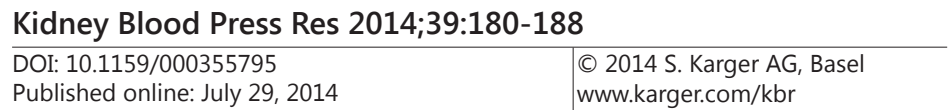

Intiso: Rehabilitation in Chronic Kidney Disease

10 El Nahas AM, Bello AK: Chronic kidney disease: the global challenge. Lancet 2005;365:331-340.

11 Negrini S, Ceravolo MG: The White Book on Physical and Rehabilitation Medicine in Europe: A contribution to the growth of our specialty with no boundaries Am J Phys Med Rehabil 2008;87:601-606.

12 Smyth A, Glynn LG, Murphy AW, Mulqueen J, Canavan M, Reddan DN, O'Donnell M: Mild chronic kidney disease and functional impairment in community-dwelling older adults. Age Ageing 2013;42:488-494.

-13 Kurella Tamura M, Covinsky K, Chertow G, Yaffe K, Landefeld C, McCulloch C: Functional status of elderly adults before and after initiation of dialysis. N Engl J Med 2009;361:1539-1547.

14 Harris LE, Luft FC, Rudy DW, Tierney WM: Clinical correlates of functional status in patients with chronic renal insufficiency.Am J Kidney Dis 1993;21:161-166.

-15 Heiwe S, Jacobson SH: Exercise training for adults with chronic kidney disease. Cochrane Database Syst Rev 2011;5:CD003236.

16 Painter P, Roshanravan B: The association of physical activity and physical function with clinical outcomes in adults with chronic kidney disease. Curr Opin Nephrol Hypertens 2013;22:615-623.

17 Bronas UG: Cochrane review: In adults with chronic kidney disease regular exercise improves physical fitness, walking capacity, heart rate and blood pressure and some nutritional parameters. Evid Based Nurs 2012;15:95-96.

18 Greenwood SA, Lindup H, Taylor K, Koufaki P, Rush R, Macdougall IC, Mercer TH: Evaluation of a pragmatic exercise rehabilitation programme in chronic kidney disease. Nephrol Dial Transplant 2012;27:III126-134.

19 Tentori F, Elder SJ, Thumma J, Pisoni RL, Bommer J, Fissell RB, Fukuhara S, Jadoul M, Keen ML, Saran R, Ramirez SP, Robinson BM: Physical exercise among participants in the Dialysis Outcomes and Practice Patterns Study (DOPPS): correlates and associated outcomes. Nephrol Dial Transplant 2010;25:3050-3062.

20 Fried LF, Lee JS, Shlipak M, Chertow GM, Green C, Ding J, Harris T, Newman AB: Chronic kidney disease and functional limitation in older people: health, aging and body composition study. J Am Geriatr Soc 2006;54:750-756.

-21 Shlipak MG, Stehman-Breen C, Fried LF, Song X, Siscovick D, Fried LP, Psaty BM, Newman AB: The presence of frailty in elderly persons with chronic renal insufficiency. Am J Kidney Dis 2004;43:861-867.

-22 Bowling CB, Muntner P, Sawyer P, Sanders PW, Kutner N, Kennedy R, Allman RM: Community Mobility Among Older Adults With Reduced Kidney Function: A Study of Life-Space. Am J Kidney Dis 2014;63:429436.

-23 Roshanravan B, Robinson-Cohen C, Patel KV, Ayers E, Littman AJ, de Boer IH, Ikizler TA, Himmelfarb J, Katzel LI, Kestenbaum B, Seliger S: Association between physical performance and all-cause mortality in CKD. J Am Soc Nephrol 2013;24:822-830.

24 Johansen KL: Exercise in the end-stage renal disease population. J Am Soc Nephrol 2007;18:1845-1854.

-25 Castaneda C, Gordon PL, Parker RC, Uhlin KL, Roubenoff R, Levey AS: Resistance training to reduce the malnutrition-inflammation complex syndrome of chronic kidney disease. Am J Kidney Dis 2004;43:607616.

-26 Kopple JD, Wang H, Casaburi R, Fournier M, Lewis MI, Taylor W, Storer TW: Exercise in maintenance hemodialysis patients induces transcriptional changes in genes favoring anabolic muscle. J Am Soc Nephrol 2007;18:2975-2986.

-27 Chin A, Paw MJ, van Uffelen JG, Riphagen I, van Mechelen W: The functional effects of physical exercise training in frail older people: a systematic review. Sports Med 2008;38:781-793.

-28 Sugawara J, Miyachi M, Moreau KL, Dinenno FA, DeSouza CA, Tanaka H: Age-related reductions in appendicular skeletal muscle mass: association with habitual aerobic exercise status. Clin Physiol Funct Imaging 2002;22:169-172.

29 Intiso D, Di Rienzo F, Russo M, Pazienza L, Tolfa M, Iarossi A, Maruzzi G: Rehabilitation strategy in the elderly. J Nephrol 2012;25:S90-95.

30 Stel VS, Smith JH, Pluijm SM, Lips P: Consequences of falling in older men and women and risk factors for health service use and functional decline. Age Ageing 2004;33:58-65.

31 Brenneman SK, Barrett-Connor E, Sajjan S, Markson LE, Siris ES: Impact of recent fracture on healthrelated quality of life in postmenopausal women. J Bone Miner Res 2006;21:809-816.

-32 Summary of the Updated American Geriatrics Society/British Geriatrics Society clinical practice guideline for prevention of falls in older persons. J Am Geriatr Soc 2011;59:148-157. 


\section{Kidney \\ Blood Pressure Research}

Kidney Blood Press Res 2014;39:180-188

DOI: $10.1159 / 000355795$

Published onlıne: July 29,2014

(C) 2014 S. Karger AG, Basel

www.karger.com/kbr

Intiso: Rehabilitation in Chronic Kidney Disease

-33 McIntyre CW, Selby NM, Sigrist M, Pearce LE, Mercer TH, Naish PF: Patients receiving maintenance dialysis have more severe functionally significant skeletal muscle wasting than patients with dialysis-independent chronic kidney disease. Nephrol Dial Transplant 2006;21:2210-2216.

-34 Sietsema KE, Amato A, Adler SG, Brass EP: Exercise capacity as a predictor of survival among ambulatory patients with end-stage renal disease. Kidney Int 2004;65:719-724.

-35 Nelson ME, Rejeski WJ, Blair SN, Duncan PW, Judge JO, King AC, Macera CA, Castaneda-Sceppa C: American College of Sports Medicine; American Heart Association. Physical activity and public health in older adults: recommendation from the American College of Sports Medicine and the American Heart Association. Circulation 2007;116:1094-1105.

36 Kosmadakis GC, Bevington A, Smith AC, Clapp EL, Viana JL, Bishop NC, Feehally J: Physical exercise in patients with severe kidney disease. Nephron Clin Pract 2010;115:c7-c16.

37 Smart N, Steele M: Exercise training in haemodialysis patients: a systematic review and meta-analysis. Nephrology (Carlton) 2011;16:626-632.

-38 Bullani R, El-Housseini Y, Giordano F, Larcinese A, Ciutto L, Bertrand PC, Wuerzner G, Burnier M, Teta D: Effect of intradialytic resistance band exercise on physical function in patients on maintenance hemodialysis: a pilot study J Ren Nutr 2011;21:61-65.

-39 Koh KP, Fassett RG, Sharman JE, Coombes JS, Williams AD: Effect of intradialytic versus home-based aerobic exercise training on physical function and vascular parameters in hemodialysis patients: a randomized pilot study. Am J Kidney Dis 2010;55:88-99.

-40 Sterky E, Stegmayr BG: Elderly patients on haemodialysis have $50 \%$ less functional capacity than genderand age-matched healthy subjects. Scand J Urol Nephrol 2005;39:423-430.

41 Collins AJ, Foley R, Herzog C, Chavers B, Gilbertson D, Ishani A, Kasiske B, Liu J, Mau LW, McBean M, Murray A, St Peter W, Xue J, Fan Q Guo H, Li Q Li S, Li S, Peng Y, Qiu Y, Roberts T, Skeans M, Snyder J, Solid C, Wang C, Weinhandl E, Zaun D, Zhang R, Arko C, Chen SC, Dalleska F, Daniels F, Dunning S, Ebben J, Frazier E, Hanzlik C, Johnson R, Sheets D, Wang X, Forrest B, Constantini E, Everson S, Eggers P, Agodoa L: Excerpts from the United States Renal Data System 2007 annual data report. Am J Kidney Dis 2008;51:S1-S320.

42 Holley JL: Age, eGFR, and CKD complications. Clin J Am Soc Nephrol 2011;6:2729-2731.

-43 Sehgal AR: Improving hemodialysis patient outcomes: a step-by-step approach. Semin Dial 2002;15:35-37.

44 Li M, Porter E, Lam R, Jassal SV: Quality improvement through the introduction of interdisciplinary geriatric hemodialysis rehabilitation care. Am J Kidney Dis 2007;50:90-97.

45 Jassal SV, Chiu E, Li M: Geriatric hemodialysis rehabilitation care. Adv Chronic Kidney Dis 2008;15:115-122.

-46 Farragher J, Jassal SV: Rehabilitation of the geriatric dialysis patient. Semin Dial 2012;25:649-656.

47 US Renal Data System: morbidity and mortality, in USRDS 2006 Annula data Report, chap 6. The National Institutes of Health, national Institute of Diabetes and Digestive and Kidney Diseases, Bethesda, MD, 2006, pp. 121-124.

48 Schell JO, Germain MJ, Finkelstein FO, Tulsky JA, Cohen LM: An integrative approach to advanced kidney disease in the elderly. Adv Chronic Kidney Dis 2010;17:368-377. 